\title{
Turnover and the Model of Coordinated Action (MoCA)
}

Scott D. Mainwaring Independent Researcher Portland, OR 97202 USA scottmainwaring@gmail.com

\author{
Charlotte $\mathbf{P}$. Lee \\ Dept. of Human Centered Design \& \\ Engineering \\ University of Washington \\ Seattle, WA 98195 USA \\ cplee@uw.edu
}

\begin{abstract}
This work is concerned with furthering the theoretical development of one of the seven dimensions of the Model of Coordinated Action (MoCA): turnover. Turnover is an under-researched area, particularly in $\mathrm{HCI}$ and CSCW, so we survey how turnover and related concepts have been theorized and researched in other fields of inquiry such as organization studies, human resource management, knowledge management, customer relationship management, and marketing.
\end{abstract}

Permission to make digital or hard copies of part or all of this work for personal or classroom use is granted without fee provided that copies are not made or distributed for profit or commercial advantage and that copies bear this notice and the full citation on the first page. Copyrights for third-party components of this work must be honored. For all other uses, contact the Owner/Author. Copyright is held by the owner/author(s)

CSCW '17 Companion, Feb. 25 - March 01, 2017, Portland, OR, USA ACM 978-1-4503-4688-7/17/02

http://dx.doi.org/10.1145/3022198.3026359

\author{
Author Keywords \\ CSCW, HCI, theory, collaboration, turnover
}

\section{ACM Classification Keywords}

Human-centered computing, Computer supported

cooperative work

\section{Introduction}

This work is developing a part of a conceptual framework for CSCW: the Model of Coordinated Action or MoCA [9]. MoCA is a framework for describing a greater diversity of complex collaborative situations and environments including, but not limited to, collaborations that have diverse memberships that may be very short-lived and/or very long-lived and that have emerging practices. The model was created in order to better map the larger design space that reflects today's CSCW challenges of supporting not only small, homogeneous groups, but also larger, heterogeneous groups who might come from different expert communities [8]. MoCA describes coordinative actions as having seven dimensions: synchronicity, physical distribution, scale, number of communities of practice (or expertise), nascence, planned permanence, and turnover. 


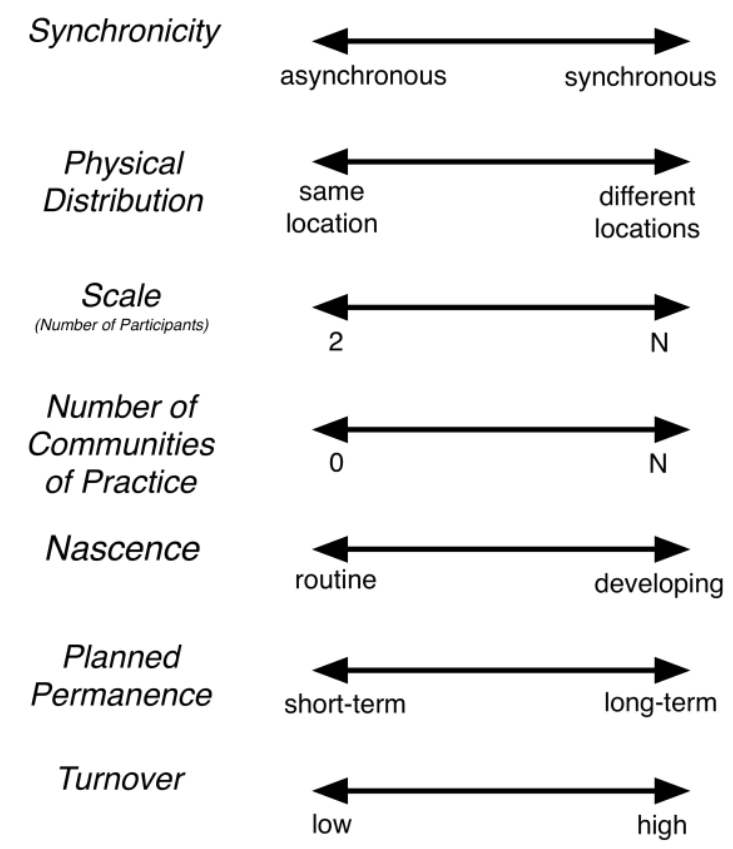

Figure 1. The Model of Coordinated Action (MoCA) and its seven dimensions with the end points of each continuum.

This work is concerned with furthering the theoretical development of one of the seven dimensions of MoCA: turnover. Turnover is characterized as concerning both the rapidity and ease with which people enter and leave a collaboration. Collaborations with low turnover may be characterized by stability, closed boundaries, and perhaps formally defined participant roles (e.g. student project groups). Situations of high turnover are found in more emergent collaborations characterized by mass participation, porous boundaries, and tolerance for rapidly changing membership (e.g. crowdsourced disaster response [16]).
Turnover is an under-researched area, particularly in $\mathrm{HCI}$ and $\mathrm{CSCW}$, so we started by surveying how turnover (and related concepts) have been theorized and researched in other fields of inquiry. To this end we led a directed research group of students at the University of Washington to discuss readings sampled from fields such as organization studies, human resource management, knowledge management, customer relationship management, and marketing. We present this exploratory work in progress.

\section{Employee Turnover}

There is a huge body of research in organizational and management studies looking at employee turnover across the whole range of industries comprising developed economies. The focus has been on the retention of valuable employees in the face of pushes and pulls that may lead to their leaving, turnover being seen as a costly threat to productivity and profitability, and to effective knowledge management.

Much of the work has been in the bounded rationality tradition of March and Simon [10], focusing on individual stay vs. leave decisions. Mowday, Porter, and Steers [12] present a model centered on job satisfaction and the discovery and evaluation of alternatives. Mitchell and Lee's "unfolding model" [13] extends this approach by emphasizing the role of "shocks" that can trigger employees to leave, and five distinct "paths" they may take out of their jobs differing by the degree and nature of their mental deliberations. In contrast Nyberg and Ployhart [14] analyze emergent effects of turnover on group-level human capital resources conceptualized as pools of KSAOs (employee knowledge, skills, abilities, and other characteristics), that may be to the group's detriment or betterment 
depending on outflows and inflows, and the complexity and interdependency of the group's work processes.

\section{Onboarding}

Strangely disconnected from this turnover literature looking at employee departures are studies of onboarding, processes for bringing new employees or customers into an organization or service. And unlike the predominantly individualized focus of turnover studies, onboarding research has been much influenced by the apparent effectiveness of institutionalized, standardized orientation rituals over more "sink or swim" alternatives placing the onus on each employee to find their own way $[17,7,1]$. (In looking at editors joining WikiProjects on Wikipedia, Choi et al. [3] found somewhat contradictory evidence for the importance of personal outreach vs. entirely automated/standardized welcoming methods.)

Sometimes the question is less about how to assimilate new employees into existing structures and more how new employees brought in all at once can grow and transform a company. For example, this has been a focus of studies of start-ups "scaling up" through specialization and institutionalization [6].

\section{Churn}

Analogous to efforts to minimize costly turnover of employees, a large literature in marketing and customer relationship management (CRM) has looked minimizing costly churn (customers or users abandoning ongoing use of a product or service) $[13,5]$. Often the focus has been on large-scale ICTbased (or at least ICT-monitored) services, ranging from network service providers, to mass retailers, to crowdsourcing enterprises, and data-focused, quantitative, machine-learning approaches these afford. In online services the concern is newcomer churn: how to maintain a growing user base in the face of most users leaving after only a few initial encounters $[4,15]$.

\section{Communities of Practice}

A very different point of departure for considering turnover is Wenger's work on communities of practice [18]. We consider it here aside from the quantitative dimension (number of communities of practice) discussed earlier. He emphasizes the social, dynamic, constantly mutually negotiated nature of "a kind of community created over time by the sustained pursuit of a shared enterprise", and the importance of incorporating newcomers not just by formal onboarding but through "legitimate peripheral participation" (often leading to more central membership). From Wenger's perspective, turnover in the form of shifting identities, roles, and centrality is a normal and continual learning process, not necessarily a dysfunctional phenomenon to be avoided or mitigated.

\section{Future Work: Lenses on Coordinated Action}

In developing MoCA, the question is how these different research traditions and perspectives on people coming and going from certain well-studied work and consumption contexts can inform how the field of CSCW understands the comings and goings of participants in the types of coordinated actions it considers central to its historical, current, and future interests. In some cases, the relevance may be direct as the potential for applying a human capital, resource based view of KSAOs to the dynamics of any coordinated action. In others, the relevance may be through analogy, or opposition. This review of literature 
undertaken in conversation with a student reading group is only the first step in a more critical, comparative analysis.

\section{Acknowledgements}

Thanks to Ria Athavia, Brandon Hong, Samuelle Saliba, and Toni Ferro for brainstorming with us. Thanks also to the MoCA Team: Andrew Neang, Michael Beach, and Valerie Najera. This work supported in part by NSF grants ACI-1302272, IIS-0954088, and OCI-1220269.

\section{References}

1. Bauer, T.N. \& Erdogan, B. (2011). Organizationa socialization: The effective onboarding of new employees. In Zedeck, S. (Ed.), APA handbook of industrial and organizational psychology, Vol 3: Maintaining, expanding, and contracting the organization (pp. 51-64). American Psych. Assn.

2. Bietz, M.J., Ferro, T., \& Lee, C.P. (2012). Sustaining the development of cyberinfrastructure: an organization adapting to change. Proc. CSCW 2012.

3. Choi, B., Alexander, K., Kraut, R.E., \& Levine, J.M. (2010). Socialization tactics in Wikipedia and their effects. In Proc. CSCW 2010, 107-116.

4. Dror, G., Pelleg, D., Rokhlenko, O., \& Szpektor, I. (2012). Churn prediction in new users of Yahoo! Answers. In WWW 2012 Companion.

5. Gerdeman, D. (2013). A smarter way to reduce customer churn. Forbes/HBS Working Knowledge.

6. Gulati, R. \& DeSantola, A. (2016). Start-Ups That Last. Harvard Business Review (March 2016).

7. Jones, G. R. (1986). Socialization tactics, selfefficacy, and newcomers' adjustments to organizations. Academy of Management Journal, 29, 262-279.

8. Lee, C.P. (2007). Boundary negotiating artifacts: Unbinding the routine of boundary objects and embracing chaos in collaborative work. Computer Supported Cooperative Work, 16, 307-339.

9. Lee, C.P. \& Paine, D. (2015). From the matrix to a model of coordinated action (MoCA): A conceptual framework of and for CSCW. Proc. CSCW 2015.

10. March, J. G. \& Simon, H. (1958). Organizations. Wiley.

11. Mitchell, T.R. \& Lee, T.W. (2001). The unfolding model of voluntary turnover and job embeddedness: Foundations for a comprehensive theory of attachment. Research in Organizational Behavior, 23, 189-246.

12. Mowday, R.T., Porter, L.W., \& Steers, R.M. (1982). Chapter 5: Determinants of employee turnover (pp. 107-133). In Employee-Organization Linkages: The Psychology of Commitment, Absenteeism, and Turnover. Academic Press.

13. Ngai, E.W.T., Xiu, L., \& Chau, D.C.K. (2009) Application of data mining techniques in customer relationship management: A literature review and classification. Expert Systems with Applications, 36 2592-2602.

14. Nyberg, A.I. \& Ployhart, R.E. (2013). Contextemergent turnover (CET) theory: A theory of collective turnover. Academy of Management Review, $38,109-131$.

15. Pudipeddi, J.S., Akoglu, L., \& Tong, H. (2014). User churn in focused question answering sites: characterizations and predictions. In WWW '14 Companion.

16. Starbird, K. \& Palen, L. (2013). Working and sustaining the virtual "Disaster Deck". Proc. CSCW 2013.

17. Van Maanen, J. \& Schein, E. H. (1979). Toward a theory of organizational socialization. Research in Organizational Behavior, 1, 209-264.

18. Wenger, E. (1998). Communities of Practice: Learning, Meaning, and Identity. Cambridge University Press. 